\title{
High-Performance Ternary Organic Solar Cells Enabled by Combining Fullerene and Nonfullerene Electron Acceptors
}

\author{
Jianyun Zhang ${ }^{\triangleright a, b}$ \\ Wenrui Liu ${ }^{\triangleright a, b}$ \\ Shengjie $X^{* a}$ \\ Xiaozhang Zhu*a,b \\ a Beijing National Laboratory for Molecular Sciences, CAS Key Laboratory of Organic \\ Solids, Institute of Chemistry, Chinese Academy of Sciences, Beijing 100190, China \\ ${ }^{\mathrm{b}}$ School of Chemistry and Chemical Engineering, University of Chinese Academy of \\ Sciences, Beijing 100049, China \\ xzzhu@iccas.ac.cn; xushengjie@iccas.ac.cn
}

Jianyun Zhang and Wenrui Liu contributed equally to this work.

Accepted after revision: 15.08 .2019

DOI: 10.1055/s-0039-1700848; Art ID: om-19-0006-oa Hecesse tems: $@(1) \Theta \Theta$

(c) 2019. The Author(s). This is an open access article published by Thieme under the terms of the Creative Commons Attribution-NonDerivative-NonCommercial-License, permitting copying and reproduction so long as the original work is given appropriate credit. Contents may not be used for commercial purposes, or adapted, remixed, transformed or built upon. (https://creativecommons.org/licenses/by-nc-nd/4.0/)

Abstract Recently, by elaborately designing nonfullerene acceptors and selecting suitable polymer donors great progresses have been made towards binary organic solar cells (OSCs) with power conversion efficiencies (PCEs) over 15\%. Ternary organic photovoltaics by introducing a third component into the host binary system is recognized to be highly effective to elevate the performance through extending the light absorption, manipulating the recombination behavior of the carriers, and improving the morphology of the active layer. In this work, we synthesized a new electron-acceptor ZITI-4F matching it with the widebandgap polymer donor PBDB-T The PBDB-T:ZITI-4F-based OSC showed a high PCE of $12.33 \%$. After introducing $40 \%$ of $\mathrm{PC}_{71} \mathrm{BM}$ as the third component, the ternary device achieved an improved PCE of $13.40 \%$ with simultaneously improved photovoltaic parameters. The higher performance of the ternary device can be attributed to the improved and more balanced charge mobility, reduced bimolecular recombination, and more favorable morphology. These results indicate that the cooperation of a fullerene-based acceptor and a nonfullerene acceptor to fabricate ternary OSCs is an effective approach to optimizing morphology and therefore to increase the performance of OSCs.

Key words ternary organic solar cells, electron acceptors, indenoindene, power conversion efficiencies

\section{Introduction}

Bulk-heterojunction organic solar cells (BHJ-OSCs) as a promising technology for clean and renewable energy conversion have attracted increasing attention because of their great potential of light weight, semi-transparency, flexibility, and large-area production. ${ }^{1}$ In recent years,

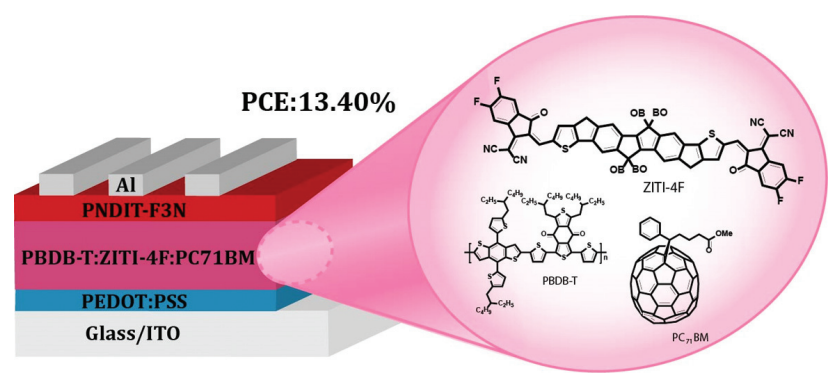

nonfullerene electron acceptors with an acceptor-donoracceptor (A-D-A) framework have aroused considerable interest because of their adjustable energy levels, tunable bandgaps, and feasible synthesis. ${ }^{2}$ By elaborately designing nonfullerene acceptors and selecting appropriate polymer donors, a great progress has been achieved leading to high power conversion efficiencies (PCEs). ${ }^{3}$

The ternary organic photovoltaic technique of incorporating a third photoactive component is effective to address the intrinsic defect of BHJ-OSCs, which utilize binary active blends with insufficient sunlight collection capability due to their intrinsically narrow absorption of organic conjugated materials. ${ }^{4}$ Ensuring that efficient exciton dissociation and charge collection are guaranteed, improved short-circuit current $\left(J_{\mathrm{sc}}\right)$ and fill factor (FF) can be expected. ${ }^{5}$ Moreover, emerging fused-ring electron acceptors (FREAs) with low open-circuit voltage $\left(V_{\text {oc }}\right)$ loss and highly tunable electronic structure represent a new opportunity to enriche ternary organic photovoltaics (OPVs). Blend combinations of donor/FREA/fullerene, ${ }^{6}$ (donor)2/FREA, ${ }^{7}$ and donor/(FREA) $2^{8}$ have been extensively explored leading to improved photovoltaic performance. Recently, fullerene-based acceptors such as [6,6]-phenyl- $\mathrm{C}_{61 / 71}$-butyric acid methyl ester ( $\left.\mathrm{PC}_{61 / 71} \mathrm{BM}\right)$, bis-adduct of phenyl- $\mathrm{C}_{71}$-butyric-acid-methyl ester (bis-PC ${ }_{70} \mathrm{BM}$ ), and indene-C60 bisadduct (ICBA) have been introduced as third components into the nonfullerene binary OSCs for high photovoltaic performance. Hou et al fabricated high performance ternary OSCs, which for the $12.2 \%$ are based on polymer donor like poly[ $(2,6-(4,8-$ bis(5-(2-ethylhexyl)thiophen-2-yl)-benzo[1,2-b:4,5-b'] dithiophene ))-alt-(5,5-(1',3'-di-2-thienyl-5',7'-bis(2-ethylhexyl)benzo[1',2'-c:4',5'-c']dithiophene-4,8-dione)] (PBDBT), 2,2'-[[6,6,12,12-Tetrakis(4-hexylphenyl)-6,12-dihydrodithieno[2,3-d:2',3'-d']-s-indaceno[1,2-b:5,6-b']dithiophene2,8-diyl]bis[2-(5-methyl-3-oxo-2,3-dihydro-1H-inden-1ylidene)malononitrile] (IT-M), and bis[70]PCBM. ${ }^{9}$ Chen and coworkers reported a small-bandgap FREA, 2,2'-[[6,6,12, 12Tetrakis(4-ethylhexylphenyl)-6,12-dihydrodithieno[2,3- 
$\left.\mathrm{d}: 2^{\prime}, 3^{\prime}-\mathrm{d}^{\prime}\right]$-s-indaceno[1,2-b:5,6-b']dithiophene-2,8-diyl] bis[2-(5,6-difluoro-3-oxo-2-2,3-dihydro-1H-ioden-1-ylidene)malononitrile] (3TT-FIC), ${ }^{10}$ which matched with a low-bandgap polymer donor, poly[4,8-bis(5-(2-ethylhexyl) thiophen-2-yl)benzo[1,2-b:4,5-b']dithiophene-co-3-fluorothieno[3,4-b]thiophene-2-carboxylate] (PTB7-Th), achieving a high $\mathrm{PCE}$ of $12.21 \%$. When $\mathrm{PC}_{71} \mathrm{BM}$ was used as the third component, a much higher PCE of $13.54 \%$ is achieved in the ternary device. By using a wide-bandgap polymer PBT1-C as the donor, a crystalline FREA ITIC-2Cl, and an amorphous fullerene derivative ICBA as the acceptors, the blend morphology was optimized, Sun and coworkers obtained an impressive PCE of $13.4 \%$ with a high FF of $76.8 \%{ }^{11}$ These results indicate that the cooperation of a fullerene-based acceptor and a nonfullerene acceptor to fabricate a ternaryblend device may be a promising way to controlling morphology and enhancing the performance of OSCs.

We recently reported two narrow bandgap acceptors $\mathrm{NITI}^{12}$ and $\mathrm{ZITI}^{13}$ consisting of indenoindene core. Both NITI and ZITI acceptors show excellent compatibility with donor materials and exhibit high performance. Using a combination of small-molecule donor benzodithiophene terthiophene rhodamine (BTR) with both the fullerene acceptor $\mathrm{PC}_{71} \mathrm{BM}$ and NITI, we achieved a high PCE of $13.63 \%$ for ternary solar cells, which forms a hierarchical morphology consisting of a PCBM transporting highway and an intricate nonfullerene phase-separated pathway network. ${ }^{14}$ In this work, we synthesized a nonfullerene acceptor ZITI-4F via the Knoevenagel reaction of INCN-2F and ZIT-CHO. ZITI-4F shows a very high molar extinction coefficient $(\varepsilon)$ of $2.46 \times 10^{5} \mathrm{M}^{-1} \mathrm{~cm}^{-1}$ at $716 \mathrm{~nm}$ in solution with a low optical band of $1.47 \mathrm{eV}$. By matching with the wide-bandgap polymer donor PBDB-T, the optimized PBDB-T:ZITI-4F-based devices achieve a high PCE of $12.33 \%$ with an open-circuit voltage $\left(V_{\text {oc }}\right)$ of $0.80 \mathrm{~V}$, a short circuit current density $\left(J_{\mathrm{sc}}\right)$ of $21.17 \mathrm{~mA} \mathrm{~cm}^{-2}$, and a FF of $73.27 \%$. To further promote the OPV performance, $\mathrm{PC}_{71} \mathrm{BM}$ was added into the device as a third component, and the ternary devices achieved a higher PCE of up to $13.40 \%$ with simultaneously elevated $V_{\text {oc }}(0.82 \mathrm{~V}), J_{\mathrm{sc}}\left(22.04 \mathrm{~mA} \mathrm{~cm}{ }^{-2}\right)$, and $\mathrm{FF}(74.24 \%)$. The recombination and morphology analyses indicate that the higher performance of ternary device can be attributed to the improved and more balanced charge mobility, reduced bimolecular recombination, and more favorable morphology.

\section{Results and Discussion}

The synthetic route of compound ZITI-4F is shown in Figure S1 (see the Supporting Information). A dialdehyde precursor was prepared according to the reported procedure. ${ }^{13}$ The target molecule ZITI-4F was synthesized via a Knoevenagel reaction between the dialdehyde and 2-(5,6difluoro-3-oxo-2,3-dihydro- $1 \mathrm{H}$-inden-1-ylidene)malono- nitrile ( $2 \mathrm{~F}-\mathrm{INCN}-2 \mathrm{~F}$ ) in $76 \%$ yield as a black solid. ZITI-4F is fully characterized by conventional nuclear magnetic resonance (NMR), mass, and elemental analyses, and the detailed characterization data are given in the Supporting Information. ZITI-4F exhibits good solubility in commonly used device-processing solvents, such as chloroform, chlorobenzene, and o-dichlorobenzene. Thermal gravity analysis (TGA) of ZITI-4F under a nitrogen atmosphere shows good thermal stability with a high decomposition temperature of $321{ }^{\circ} \mathrm{C}$ ( $5 \%$ weight loss; see Figure S2 in the Supporting Information).

The ultraviolet-visible-near infrared (UV-vis-NIR) absorption spectra of ZITI-4F in chloroform solution and in the film state are shown in Figure 1b. ZITI-4F shows an absorption maximum at $716 \mathrm{~nm}$ with an extinction coefficient $(\varepsilon)$ of $2.46 \times 10^{5} \mathrm{M}^{-1} \mathrm{~cm}^{-1}$. In the film state, the absorption spectrum becomes broadened with the maximum absorption peak bathochromically shifted to $768 \mathrm{~nm}$, which suggests that strong $\pi-\pi$ intermolecular interactions are present in the solid state. The optical bandgap of ZITI-4F is calculated to be $1.47 \mathrm{eV}$ according to the thin-film absorption onset ( $846 \mathrm{~nm})$. ZITI-4F shows a perfect complementary absorption with the wide-bandgap polymer donor PBDB-T. Cyclic voltammetry measurement was carried out to evaluate the electrochemical property of ZITI-4F (see Figure S2 in the Supporting Information) and the corresponding energy diagram is presented in Figure 1c. The potential is calibrated by using ferrocene/ferrocenium $\left(\mathrm{Fc} / \mathrm{Fc}^{+}\right.$) redox couple (4.8 eV under vacuum energy level) as the reference. The HOMO and LUMO energy levels are estimated by the oxidation and reduction onsets to be -5.65 and $-3.81 \mathrm{eV}$, respectively.

The photovoltaic performance of ZITI-4F was investigated and optimized based on a conventional device structure of indium tin oxide (ITO)/poly(3,4-ethylenedioxythiophene): poly(styrenesulfonate)(PEDOT:PSS)/active layer/PNDIT-F3$\mathrm{N} / \mathrm{Al}$, in which PBDB-T was used as the electron donor and PEDOT:PSS and PNDIT-F3N served as the anode and cathode buffer layers to promote charge collection at electrodes, respectively. The optimization procedures involved $\mathrm{D}$ :A ratios (from 1:0.8 to 1:1.2), thermal annealing temperature, and film thickness (see Tables S1-S3 in the Supporting Information). The devices were fabricated by a spin-coating method. Chloroform was utilized as the processing solvent with a total concentration of $17 \mathrm{mg} / \mathrm{mL}$. The optimal D/A weight ratio was determined to be $1: 1$. The current density-voltage $(J-V)$ curves of both optimized devices are shown in Figure $2 a$. The PBDB-T:ZITI-4F-based device after thermal annealing treatment at $110{ }^{\circ} \mathrm{C}$ for 10 min showed a high PCE of $12.33 \%$ with a $V_{\text {oc }}$ of $0.80 \mathrm{~V}, \mathrm{a} J_{\mathrm{sc}}$ of $21.17 \mathrm{~mA} \mathrm{~cm}^{-2}$, and a FF of $73.27 \%$. By contrast, the PBDB-T:PC ${ }_{71} \mathrm{BM}$-based device yielded a moderate PCE of $7.82 \%$ due to the low $J_{\mathrm{sc}}$ of $12.32 \mathrm{~mA} \mathrm{~cm}^{-2}$, regardless of a higher $V_{\text {oc }}$ of $0.88 \mathrm{~V}$ and $\mathrm{FF}$ of $72.32 \%$. Then, we added $\mathrm{PC}_{71} \mathrm{BM}$ as the third component to construct ternary 

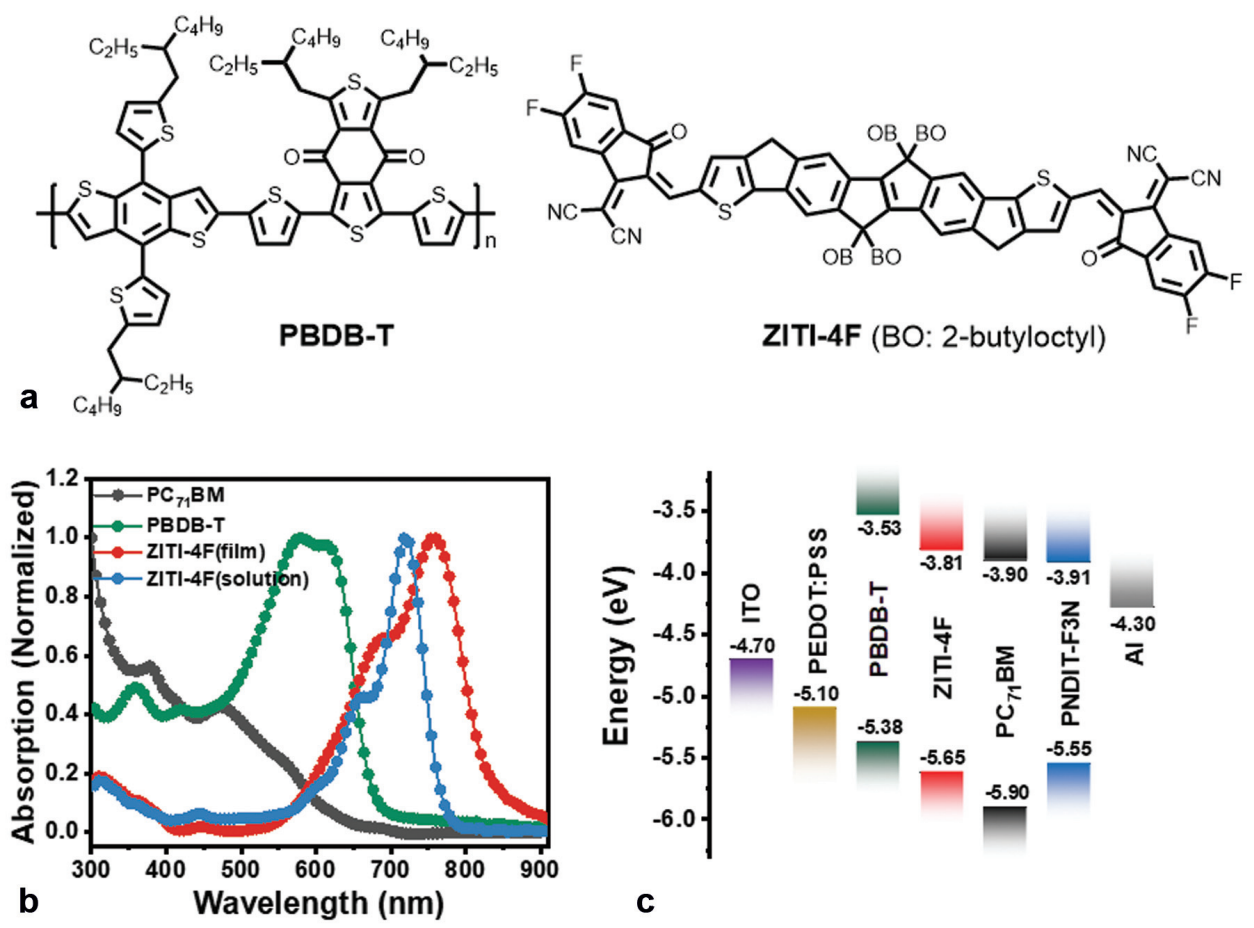

Fig. 1 (a) Molecular structures of PBDB-T and ZITI-4F. (b) UV-vis-NIR absorption spectra of ZITI-4F in chloroform and thin films and PBDB-T and PC ${ }_{71}$ BM in thin films. (c) Energy diagram of materials used in OPV devices.

devices. Based on the same device structure wherein the ternary solar cells were constructed with the photoactive layer consisting of PBDB-T:ZITI-4F:PC ${ }_{71} \mathrm{BM}(\mathrm{D}: \mathrm{A} 1: \mathrm{A} 2)$, the D: $A 1$ ratio was kept at $1: 1$ and the proportion of $\mathrm{PC}_{71} \mathrm{BM}$ was carefully optimized. The devices with different $\mathrm{PC}_{71} \mathrm{BM}$ contents exhibited consistent thicknesses of around $100 \mathrm{~nm}$. We found that with the increase of the $\mathrm{PC}_{71} \mathrm{BM}$ content, the $V_{\text {oc }}$ and $J_{\text {sc }}$ values improved slightly for all ternary devices. When the ratio of D:A1:A2 equals $1: 1: 0.4$, the ternary device attained the highest PCE of $13.40 \%$, with an increased

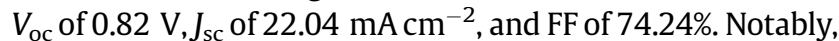
the performance of ternary OSCs is less sensitive to the content of $\mathrm{PC}_{71} \mathrm{BM}$; even when the ratios of $\mathrm{D}: \mathrm{A} 1: \mathrm{A} 2$ varies from $1: 1: 0.2$ to $1: 1: 0.8$, the resulting performances of ternary devices outperform with respect to the corresponding PBDBT:ZITI-4F-based binary device (Table 1 and Figure 2a).

The external quantum efficiency (EQE) curves of these devices are presented in Figure $2 \mathrm{~b}$. The binary device based on PBDB-T:ZITI-4F shows a much broader and higher photo response than that based on $\mathrm{PBDB}-\mathrm{T}: \mathrm{PC}_{71} \mathrm{BM}$. The $J_{\mathrm{sc}}$ value of the optimized PBDB-T:ZITI-4F-based device calculated from integration of the EQE spectrum is $20.84 \mathrm{~mA} \mathrm{~cm}^{-2}$. Compared with the binary devices, the ternary devices show higher EQE values over the whole spectral response range with the maximum value of around $81 \%$ at $840 \mathrm{~nm}$, which accounts for the enhancement in photocurrents. The current densities integrated from the EQE curves are 21.31,
21.97, 21.36, and $21.15 \mathrm{~mA} \mathrm{~cm}^{-2}$ for PBDB-T:ZITI-4F: $\mathrm{PC}_{71} \mathrm{BM}$-based devices with weight ratios of $1: 1: 0.2$, $1: 1: 0.4,1: 1: 0.6$, and 1:1:0.8, respectively (Table 1 ). These data are consistent with the $J_{\mathrm{sc}}$ values obtained from the $J-V$ curves with small errors of 1 to $2 \%$.

To unearth charge generation and extraction processes among these devices (binary devices and ternary devices), photocurrent analysis was performed. First, we measured the photocurrent density $\left(J_{\mathrm{ph}}\right)$ versus the effective voltage $\left(V_{\text {eff }}\right)$ for the binary and ternary devices. The exciton dissociation probability can be calculated by $P_{\text {diss }}=J_{\mathrm{ph}} /$ $J_{\text {sat }}$. It can be seen that $J_{\text {ph }}$ reaches saturation $\left(J_{\text {sat }}\right)$ when $V_{\text {eff }}$ values reached $\sim 2 \mathrm{~V}$, suggesting that the excitons inside those devices were dissociated. As shown in Figure 2d, all the devices exhibit high charge-extraction probability $(P)$ under the short-circuit conditions, which is $90 \%$ for binary devices. The $P_{\text {diss }}$ is $91,94,92,91 \%$ for PBDB-T:ZITI-4F: $\mathrm{PC}_{71} \mathrm{BM}$ with weight ratios of $1: 1: 0.2,1: 1: 0.4,1: 1: 0.6$, and $1: 1: 0.8$, respectively. When the weight ration of $D: A 1: A 2$ is $1: 1: 0.4, P_{\text {diss }}$ is up to $94 \%$, indicating more effective charge transport and exciton dissociation in the ternary device. Furthermore, the $J_{\text {sc }}$ at different light intensities was inspected to determine the charge recombination dynamics. In principle, the recombination parameter $(\alpha)$, defined by the equation $J_{\mathrm{sc}} \propto P^{\alpha}$, close to 1.0 suggests the neglectable bimolecular recombination. As shown in Figure 2c, the $\alpha$ values are greater than 0.94 for all the devices. Clearly, low 

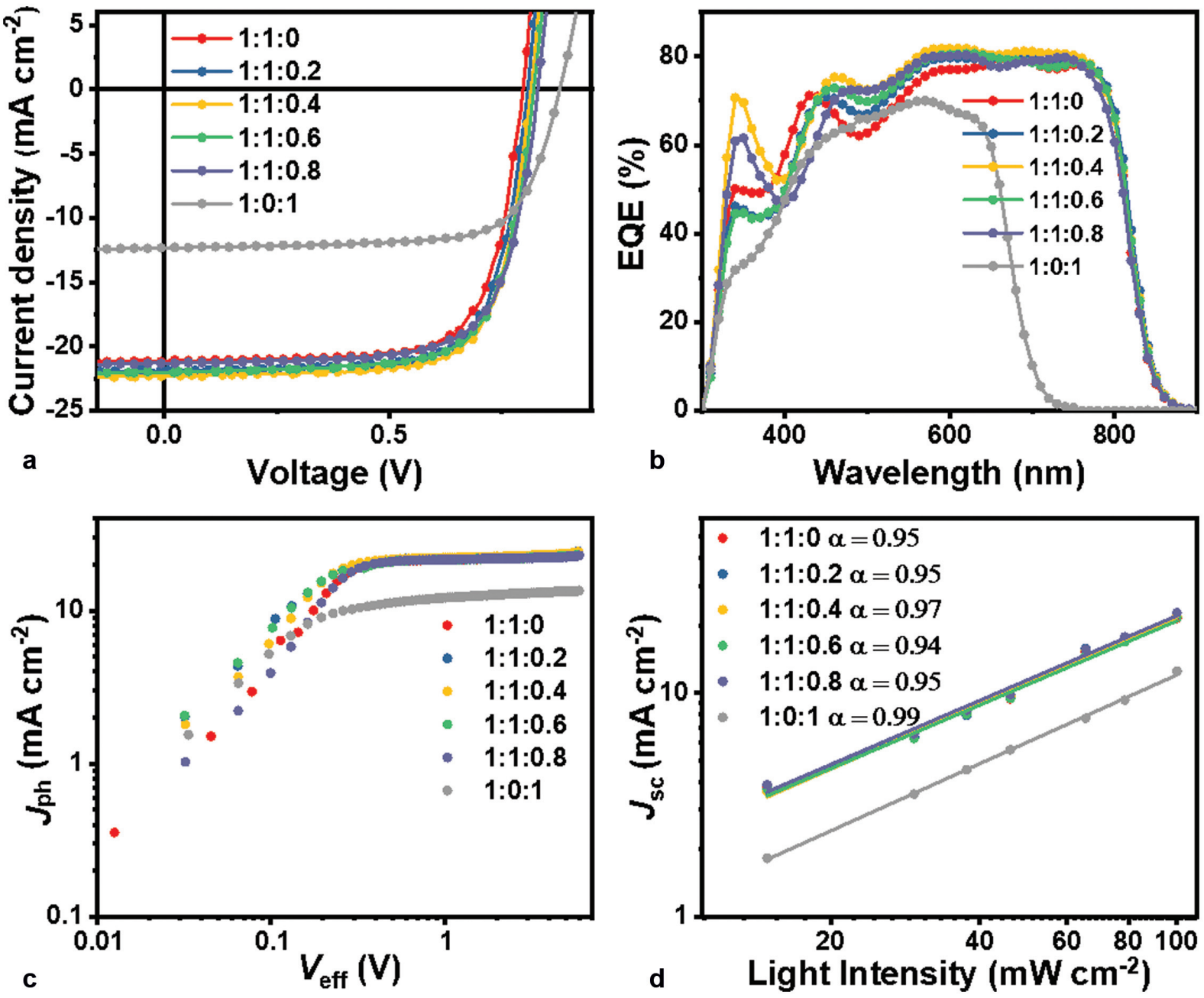

Fig. 2 (a) Characteristic J-V curves, (b) EQE curves, (c) J ph $_{\text {vs. }} V_{\text {eff }}$ plots, and (d) correlation between $\int_{\text {sc }}$ and light intensity in the optimized PBDB-T:ZITI-4Fand PBDB-T:ZITI-4F:PC 71 BM-based devices with different weight ratios.

or high contents of $\mathrm{PC}_{71} \mathrm{BM}$ do not induce more recombination centers for our ternary system, suggesting that bimolecular recombination is efficiently suppressed. For the ternary devices, the $\alpha$ is 0.97 at the optimized ratio (D: $\mathrm{A} 1: \mathrm{A} 2=1: 1: 0.4)$.
To understand the charge carrier transport property in binary and ternary devices, the $J-V$ curves of the optimized single charge carrier devices were investigated using the space-charge-limited current (SCLC) method. The hole- and electron-only device structures are ITO/ZnO/active layer/Al

Table 1 Photovoltaic parameters of PBDB-T:ZITI-4F:PC ${ }_{71} B M$ (D:A1:A2)-based devices with different weight ratios ${ }^{\mathrm{a}}$

\begin{tabular}{|c|c|c|c|c|c|c|c|c|}
\hline D:A1:A2 & $V_{\mathrm{oc}}(\mathrm{V})$ & $J_{\mathrm{sc}}\left(\mathrm{mA} \mathrm{cm}{ }^{-2}\right)$ & $J_{\text {cal }}\left(\mathrm{mA} \mathrm{cm}^{-2}\right)$ & $\mathrm{FF}(\%)$ & $\mathrm{PCE}_{\mathrm{avg}}\left(\mathrm{PCE}_{\max }\right)(\%)$ & $\mu_{\mathrm{h}}\left(\mathrm{cm}^{2} \mathrm{v}^{-1} \mathrm{~s}^{-1}\right)$ & $\mu_{\mathrm{e}}\left(\mathrm{cm}^{2} \mathrm{~V}^{-1} \mathrm{~s}^{-1}\right)$ & $\mu_{\mathrm{h}} / \mu_{\mathrm{e}}$ \\
\hline $1: 1: 0$ & 0.80 & 21.17 & 20.84 & 73.27 & $12.08 \pm 0.16(12.33)$ & $2.04 \times 10^{-4}$ & $3.09 \times 10^{-4}$ & 1.51 \\
\hline $1: 1: 0.2$ & 0.81 & 21.86 & 21.31 & 72.87 & $12.76 \pm 0.12(12.88)$ & $1.48 \times 10^{-4}$ & $2.79 \times 10^{-4}$ & 1.88 \\
\hline $1: 1: 0.4$ & 0.82 & 22.04 & 21.97 & 74.24 & $13.18 \pm 0.15(13.40)$ & $2.53 \times 10^{-4}$ & $2.94 \times 10^{-4}$ & 1.16 \\
\hline $1: 1: 0.6$ & 0.82 & 21.92 & 21.36 & 72.77 & $12.88 \pm 0.15(13.11)$ & $1.94 \times 10^{-4}$ & $3.05 \times 10^{-4}$ & 1.57 \\
\hline $1: 1: 0.8$ & 0.82 & 21.58 & 21.15 & 70.49 & $12.42 \pm 0.13(12.66)$ & $1.26 \times 10^{-4}$ & $2.82 \times 10^{-4}$ & 2.24 \\
\hline $1: 0: 1$ & 0.88 & 12.32 & 11.94 & 72.23 & $7.58 \pm 0.16(7.82)$ & $3.58 \times 10^{-4}$ & $4.48 \times 10^{-4}$ & 1.25 \\
\hline
\end{tabular}

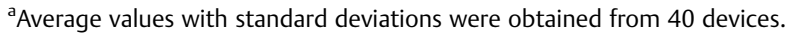



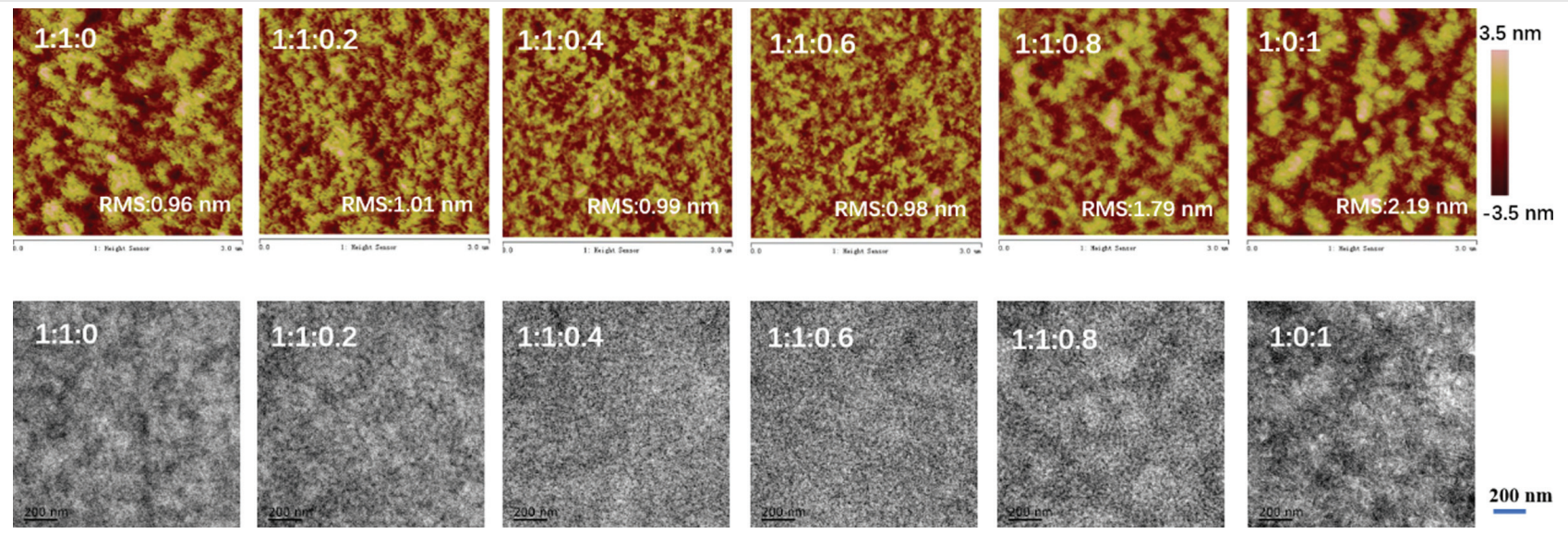

Fig. 3 AFM height images (top) and TEM (bottom) images of the blend films.

and ITO/PEDOT:PSS/active layer/Au, respectively. The $J-V$ curves are presented in Figure S3 (see the Supporting Information), and the detailed data are summarized in Table 1. The hole $\left(\mu_{\mathrm{h}}\right)$ and electron mobilities $\left(\mu_{\mathrm{e}}\right)$ of the PBDB-T:ZITI-4F-based devices are $2.04 \times 10^{-4}$ and $3.09 \times 10^{-4} \mathrm{~cm}^{2} \mathrm{~V}^{-1} \mathrm{~s}^{-1}$, respectively. The $\mu_{\mathrm{h}}$ and $\mu_{\mathrm{e}}$ values of ternary devices are $1.48 \times 10^{-4}, 2.53 \times 10^{-4}$, $1.94 \times 10^{-4}, 1.26 \times 10^{-4} \mathrm{~cm}^{2} \mathrm{~V}^{-1} \mathrm{~s}^{-1}$ and $2.79 \times 10^{-4}$, $2.94 \times 10^{-4}, 3.05 \times 10^{-4}, 2.82 \times 10^{-4} \mathrm{~cm}^{2} \mathrm{~V}^{-1} \mathrm{~s}^{-1}$ for devices based on PBDB-T:ZITI-4F:PC ${ }_{71}$ BM blends with weight ratios of $1: 1: 0.2,1: 1: 0.4,1: 1: 0.6$, and 1:1:0.8, respectively. For the best ratio (D:A1:A2 = 1:1:0.4), the ternary blend shows the most balanced $\mu_{\mathrm{h}} / \mu_{\mathrm{e}}$ ratio of 1.16 . The increased balanced charge transporting property of ternary devices is one of the reasons for the improved FF values.

As the morphology of the active layer is important for the device performance, which affects the charge transport and collection. Atomic force microscopy (AFM) and transmission electron microscopy (TEM) were used to investigate the superficial morphologies of the active layers and the influence of the $\mathrm{PC}_{71} \mathrm{BM}$ (Figure 3 ). The root mean square (RMS) surface roughness of PBDB-T:ZITI- $4 \mathrm{~F}$ is $0.96 \mathrm{~nm}$; the RMS roughness values of PBDB-T:ZITI- $4 \mathrm{~F}: \mathrm{PC}_{71} \mathrm{BM}$ (from $1: 1: 0.2$ to $1: 1: 0.6)$ are almost the same, $1.01,0.99$, and $0.98 \mathrm{~nm}$; when the ratio is $1: 1: 0.8$, the RMS increases to $1.79 \mathrm{~nm}$, which is closer to the RMS $(2.19 \mathrm{~nm})$ of the PBDB$\mathrm{T}: \mathrm{PC}_{71} \mathrm{BM}$ blend. The higher RMS indicates oversized phase separation, which is responsible for the lower FF value and is in accordance with the slightly unbalanced hole and electron mobilities. In the TEM images, the ratios range from $1: 1: 0$ to $1: 1: 0.6$, the blend films exhibit similarly homogeneous and interpenetrating networks with nanoscale phase separation, and the domain sizes were gradually reduced. When further adding the $\mathrm{PC}_{71} \mathrm{BM}$ component to a ratio of $1: 1: 0.8$, the blend film shows a large phase aggregation and the domain sizes were increased, which is bad for exciton diffusion and agrees well with the slightly lower FF. The molecular packing of neat and blend films was investigated by two-dimensional grazing-incidence wideangle X-ray scattering (2D-GIWAXS) measurements, and the corresponding in-plane (IP) and out-of-plane (OOP) line-cut profiles are shown in Figure 4. The ZITI-4F neat film shows a strong $\pi-\pi$ stacking diffraction peak (010) at $1.81 \AA^{-1}$ along the OOP direction and a sharp alkyl stacking packing (100) at $0.32 \AA^{-1}$ along the in-plane (IP) direction, corresponding to a $\pi-\pi$ stacking distance of $3.47 \AA$ and a lamellar $d$-spacing of $19.2 \AA$, suggesting the good structural order of ZITI-4F. The PBDB-T neat film shows a broad (100) diffraction peak at $0.30 \AA^{-1}$ (lamellar $d$-spacing of $21.3 \AA$ ) with wide azimuthal angle spreading and a $(010)$ diffraction peak at $1.69 \AA^{-1}(\pi-\pi$ stacking distance of $3.72 \AA)$ in the OOP direction. For the ZITI-4F:PBDB-T binary blend, the (010) $\pi-\pi$ stacking distance is $3.46 \AA \AA$ and the IP coherence length (CCL) is $7.2 \mathrm{~nm}$. The increase of $\mathrm{PC}_{71} \mathrm{BM}$ ratio clearly showed a typical diffuse reflection for at $1.35 \AA^{-1}$. When $40 \mathrm{wt} \% \mathrm{PC}_{71} \mathrm{BM}$ was added to the binary blend, the (010) $\pi-\pi$ stacking distance showed almost no change, but the IP $\mathrm{CCL}$ increased to $11.8 \mathrm{~nm}$, suggesting that the introduction of $\mathrm{PC}_{71} \mathrm{BM}$ can improve the material crystallinity, which may lead to the high $J_{\mathrm{sc}}$ and FF.

\section{Conclusion}

We synthesized a small-molecule electron acceptor ZITI$4 \mathrm{~F}$ based on the planar indenoindene-dithiophene core and $2 \mathrm{~F}-\mathrm{INCN}$ terminal. ZITI- $4 \mathrm{~F}$ has strong absorption (600$850 \mathrm{~nm}$ ) with a high extinction coefficient of $2.46 \times 10^{5}$ $\mathrm{M}^{-1} \mathrm{~cm}^{-1}$ and a low bandgap of $1.47 \mathrm{eV}$. Using the widebandgap polymer PBDB-T as the electron donor, the PBDB-T: ZITI-4F-based binary device shows a PCE of $12.33 \%$. By introducing $\mathrm{PC}_{71} \mathrm{BM}$ as the third component, the ternary device exhibits an outstanding PCE of $13.40 \%$. And AFM and 

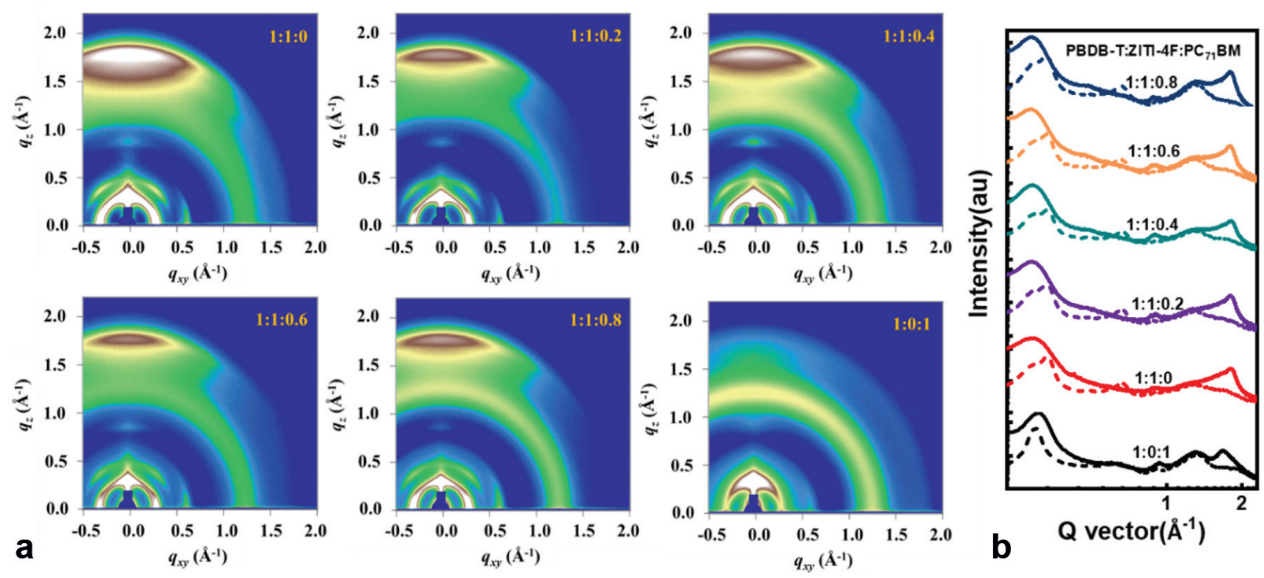

Fig. 4 (a) 2D GIWAXS patterns for PBDB-T:ZITI-4F:PC 71 BM blend films with different weight ratios. (b) The corresponding line-cuts of GIWAXS patterns (solid line: out of plane, dash line: in-plane.)

GIWAXS studies indicate that the active-layer morphology was optimized by adding $\mathrm{PC}_{71} \mathrm{BM}$. Moreover, the ZITI that has been reported by our group ${ }^{13}$ also showed a higher PCE of $13.66 \%$ for the PBDB-T:ZITI:PC71BM-based ternary device than that of the PBDB-T:ZITI-based OSC (13.03\%; Table 2). We believe that combining fullerene derivatives and nonfullerene acceptors to construct ternary OSCs should be applicable and promising for the development of highperformance OSCs in future.

\section{Experimental Section}

\section{Materials and General Methods}

All reactions involving air- or moisture-sensitive compounds were carried out in a dry reaction vessel under a positive pressure of nitrogen. Unless stated otherwise, starting materials were obtained from Adamas, Aldrich, or J\&K and were used without further purification. Anhydrous THF and toluene were distilled over $\mathrm{Na}$ /benzophenone prior to use. Anhydrous DMF was distilled over $\mathrm{CaH}_{2}$ prior to use. Compounds 1 and methyl 2-bromothiophene-3-carboxylate were prepared according to published procedures. ${ }^{1} \mathrm{H}$ and ${ }^{13} \mathrm{C}$ NMR spectra were measured with Bruker Fourier 300, or Bruker Avance 400 spectrometers. Chemical shifts for hydrogens are reported in parts per million (ppm, scale) downfield from tetramethylsilane and are referenced to the residual protons in the NMR solvent $\left(\mathrm{CDCl}_{3}\right.$ : 7.26). ${ }^{13} \mathrm{C}$ NMR spectra were recorded at $100 \mathrm{MHz}$. Chemical shifts for carbons are reported in parts per million (ppm, scale) downfield from tetramethylsilane and are referenced to the carbon resonance of the solvent $\left(\mathrm{CDCl}_{3}\right.$ : 77.2). The data are presented as follows: chemical shift, multiplicity ( $\mathrm{s}=$ singlet, $\mathrm{d}=$ doublet, $\mathrm{t}=$ triplet, $\mathrm{m}=$ multiplet and/or multiple resonances, br $=$ broad), coupling constant in hertz $(\mathrm{Hz})$, and integration. MALDI measurements were performed with a MALDI-FT 9.4 T, Bruker solariX, or MALDI-TOF MS Bruker Autoflex III. Elemental analyses were performed with a Flash EA 1112 Series from ThermoQuest. UV-vis was recorded with Jasco V-570 spectrometers. Cyclic voltammetry (CV) was performed with a CHI620D potentiostat. All measurements were carried out in a one-compartment cell under a nitrogen atmosphere, equipped with a glassycarbon electrode, a platinum counter-electrode, and an $\mathrm{Ag} / \mathrm{Ag}^{+}$reference electrode with a scan rate of $100 \mathrm{mV} / \mathrm{s}$. The supporting electrolyte was a $0.1 \mathrm{~mol} / \mathrm{L}$ dichloromethane solution of tetrabutylammonium perchlorate (TBAP). All potentials were corrected against $\mathrm{Fc} / \mathrm{Fc}^{+}$. $\mathrm{CV}$ was measured with a scan rate of $100 \mathrm{mV} / \mathrm{s}$. Thermogravimetric analysis (TGA) was performe d with a Shimadzu DTG 60 instrument at a heating rate of $10{ }^{\circ} \mathrm{C} \mathrm{min}^{-1}$ under a nitrogen

Table 2 Photovoltaic performance of PBDB-T:ZITI:PC ${ }_{71}$ BM-based solar cells

\begin{tabular}{llllll}
\hline & $V_{\text {oc }}(\mathrm{V})$ & $J_{\mathrm{sc}}\left(\mathrm{mA} \mathrm{cm}^{-2}\right)$ & $J_{\text {cal }}\left(\mathrm{mA} \mathrm{cm}^{-2}\right)$ & $\mathrm{FF}(\%)$ & $\mathrm{PCE}_{\text {avg }}\left(\mathrm{PCE}_{\text {max }}\right)(\%)^{\mathrm{a}}$ \\
\hline PBDB-T:ZITI & 0.89 & 19.80 & 19.68 & 74.04 & $12.87 \pm 0.10(13.03)$ \\
PBDB-T:ZITI:PC & 0.89 & 20.36 & 20.24 & 74.83 & $13.48 \pm 0.14(13.66)$ \\
\hline
\end{tabular}

${ }^{a}$ Average values with standard deviations were obtained from 25 devices. 
atmosphere with runs recorded from room temperature to $510{ }^{\circ} \mathrm{C}$.

\section{Fabrication of Organic Solar Cells}

The device structures were: ITO/PEDOT:PSS/PBDB-T: ZITI-4F (or PBDB-T:ZITI-4F:PC ${ }_{71}$ BM)/PNDIT-F3N/Al. Organic solar cell devices were fabricated using ITO-coated glass substrates $\left(15 \Omega \mathrm{sq}^{-1}\right)$, which were cleaned with de-ionized water, acetone, and isopropyl alcohol in successive $20 \mathrm{~min}$ sonication steps applying a final 20 min oxygen plasma treatment to eliminate any remaining organic component. A thin layer (ca. $30 \mathrm{~nm}$ ) of PEDOT:PSS (Bayer Baytron 4083) was first spin-coated on the pre-cleaned ITO-coated glass substrates at $3000 \mathrm{rpm}$ and baked at $150{ }^{\circ} \mathrm{C}$ for $15 \mathrm{~min}$ under ambient conditions. The substrates were then transferred into a nitrogen-filled glovebox. Subsequently, The active layers were spin coated from chloroform solution with the same optimal donor/acceptor $(\mathrm{D} / \mathrm{A})$ weight ratios of 1:1 for both PBDB-T:ZITI-4F (or PBDB-T:ZITI-4F:PC ${ }_{71} B M$ ) blends with a total concentration of $17 \mathrm{mg} / \mathrm{mL}$ and then treated with thermal annealing at $110{ }^{\circ} \mathrm{C}$ for $10 \mathrm{~min}$. Then PNDIT- $\mathrm{F}_{3} \mathrm{~N}$ as the electron transporting layer was spincoated on the active layer by $3000 \mathrm{rpm}$ from alcohol solution. At the final stage, the substrates were pumped down in high vacuum, and aluminum (100 nm) was thermally evaporated onto the active layer. Shadow masks were used to define the OSC active area $\left(0.05 \mathrm{~cm}^{2}\right)$ of the devices.

\section{Device Characterization}

The current density-voltage $(\mathrm{J}-\mathrm{V})$ characteristics of unencapsulated photovoltaic devices were measured under $\mathrm{N}_{2}$ using a Keithley 2400 source meter. A $300 \mathrm{~W}$ xenon arc solar simulator (Oriel) with an AM 1.5 global filter operated at $100 \mathrm{~mW} \mathrm{~cm}^{-2}$ was used to simulate the AM $1.5 \mathrm{G}$ solar irradiation. The illumination intensity was corrected by using a silicon photodiode with a protective KG5 filter calibrated by the National Renewable Energy Laboratory (NREL). The external quantum efficiency (EQE) was performed using certified IPCE equipment (Zolix Instruments, Inc, SolarCellScan100).

\section{SCLC Mobility Measurements}

Space charge-limited currents were tested in electrononly devices with a configuration of ITO/ZnO/ PBDB-T:ZITI4F (or PBDB-T:ZITI-4F:PC ${ }_{71} \mathrm{BM}$ )/Al and hole-only devices with a configuration of ITO/PEDOT:PSS/ PBDB-T:ZITI-4F (or PBDB-T:ZITI-4F:PC $\left.{ }_{71} \mathrm{BM}\right) / \mathrm{Au}$. The devices were prepared following the same procedure described in the experimental section for photovoltaic devices, except for the metal electrode. The mobilities were determined by fitting the dark current to the model of a single carrier SCLC current with field dependent mobility, which is described as

$$
J=\frac{9 \varepsilon_{0} \varepsilon_{\mathrm{r}} \mu_{0} V^{2}}{8 L^{3}}
$$

where $J$ is the current, $\mu_{0}$ is the zero-field mobility, $\varepsilon_{0}$ is the permittivity of free space, $\varepsilon_{\mathrm{r}}$ is the relative permittivity of the material, $V$ is the effective voltage, and $L$ is the thickness of the active layer.

\section{Microstructure Investigation}

Atomic force microscopy (AFM) images of the thin films were obtained on a NanoscopeIIla AFM (Digital Instruments) operating platform in tapping mode. Transmission electron microscopy (TEM) observation was performed on JEOL 2200FS at $160 \mathrm{kV}$ accelerating voltage. Grazing incidence X-ray diffraction characterization of the thin films was performed at the SSRL on beamline 11-3, Standford Synchrotron Radiation Lab. Thin film samples were spin-casted on to PEDOT:PSS covered $\mathrm{SiO}_{2}$ wafers. The scattering signal was recorded on a 2D detector (MarCCD). The samples were $\approx 15 \mathrm{~mm}$ long in the direction of the beam path, and the detector was located at a distance of $\approx 300 \mathrm{~mm}$ from the sample center (distance calibrated using a silver behenate standard). The incidence angle of $0.16^{\circ}$ was chosen which gave the optimized signal-to-background ratio. The beam energy was $8 \mathrm{keV}$. All GIWAXS experiments were done in helium atmosphere. The data was processed and analyzed using waxdiff software package.

\section{Synthetic Part}

Compound ZITI-4F. INCN-2F ( $83 \mathrm{mg}, 0.36 \mathrm{mmol}$ ) and ZIT-CHO (100 mg, $0.09 \mathrm{mmol}$ ) were added to a solvent mixture of chloroform $(10 \mathrm{~mL})$ and pyridine $(0.2 \mathrm{~mL})$. The reaction was placed in an oil bath at $75{ }^{\circ} \mathrm{C}$ and was stirred overnight. The mixture was directly purified on a silica-gel column chromatography using trichloromethane as eluent to give $106 \mathrm{mg}$ of ZITI-4F as black solid (76\%). ZITI-4F: ${ }^{1} \mathrm{H}$ NMR (400 MHz, $\left.\mathrm{CDCl}_{3}\right): 8.96(\mathrm{~s}, 2 \mathrm{H}), 8.55(\mathrm{~m}, 2 \mathrm{H}), 7.92(\mathrm{~s}$, $2 \mathrm{H}), 7.79(\mathrm{~s}, 2 \mathrm{H}), 7.68(\mathrm{t}, 3 \mathrm{~J}=7.6 \mathrm{~Hz}, 2 \mathrm{H}), 7.57(\mathrm{~s}, 2 \mathrm{H}), 3.88$ $(\mathrm{s}, 4 \mathrm{H}), 2.13(\mathrm{~s}, 8 \mathrm{H}), 1.300 .50(\mathrm{~m}, 92 \mathrm{H}) ;{ }^{13} \mathrm{C}$ NMR $\left(150 \mathrm{MHz}, \mathrm{CDCl}_{3}\right): 185.5,164.5,158.4,158.2,156.5$, $154.8,154.7,153.0,152.9,147.9,142.1,139.4,138.1$, $136.1,134.1,133.9,119.5,116.8,116.4,114.5,114.3$, $114.1,114.0,112.0,111.8,76.5,76.3,68.1,53.7,42.6,42.4$, $34.7,34.4,34.1,33.4,33.1,31.5,31.3,31.3,29.3,29.2,27.9$, 
27.2, 27.1, 25.6, 25.6, 24.8, 24.7, 22.6, 22.3, 22.1, 22.1, 13.5, $13.5,13.3$; HRMS (MALDI-TOF) calcd for $\mathrm{C}_{100} \mathrm{H}_{116} \mathrm{~F}_{4} \mathrm{~N}_{4} \mathrm{O}_{2} \mathrm{~S}_{2}$ $[\mathrm{M}]^{+}$: 1544.8470, found, 1544.8479. Anal. Calcd for $\mathrm{C}_{100} \mathrm{H}_{116} \mathrm{~F}_{4} \mathrm{~N}_{4} \mathrm{O}_{2} \mathrm{~S}_{2}$ (\%): C, 77.68; $\mathrm{H}, 7.56 ; \mathrm{N}, 3.62$; found: C, 77.38; H, 7.53; N, 3.77.

\section{Funding Information}

The authors would like to thank the National Basic Research Program of China (973 Program; No. 2014CB643502), the Strategic Priority Research Program of the Chinese Academy of Sciences (XDB12010200), and the National Natural Science Foundation of China (91333113, 21572234, 91833304, and 21805289) for the financial support.

\section{Acknowledgement}

The authors appreciate Prof. Changduk Yang and Dr. Shanshan Chen at Department of Energy Engineering, School of Energy and Chemical Engineering, Perovtronics Research Center, Low Dimensional Carbon Materials Center, Ulsan National Institute of Science and Technology (UNIST) for GIWAXS measurements.

\section{Supporting Information}

Supporting information for this article is available online at https://doi.org/10.1055/s-0039-1700848.

\section{References}

(1) (a) Li, G.; Zhu, R.; Yang, Y. Nat. Photonics 2012, 6, 153. (b) Li, G.; Shrotriya, V.; Huang, J., et al. Nat. Mater. 2005, 4, 864. (c) Yu, G.; Gao, J.; Hummelen, J. C.; Wudl, F.; Heeger, A. J. Science 1995, 270, 1789. (d) Cheng, Y-J.; Yang, S-H.; Hsu, C-S. Chem. Rev. 2009, 109, 5868. (e) Lu, L.; Zheng, T.; Wu, Q.; Schneider, A. M.; Zhao, D.; Yu, L. Chem. Rev. 2015, 115, 12666.

(2) (a) Nielsen, C. B.; Holliday, S.; Chen, H-Y.; Cryer, S. J.; McCulloch, I. Acc. Chem. Res. 2015, 48, 2803. (b) Zhang, G.; Zhao, J.; Chow, P. CY., et al. Chem. Rev. 2018, 118, 3447. (c) Yan, C.; Barlow, S.; Wang, Z., et al. Nat. Rev. Mater. 2018, 3, 18003.

(3) (a) Fei, Z.; Eisner, F. D.; Jiao, X., et al. Adv. Mater. 2018, 30, 1705209. (b) Huang, C.; Liao, X.; Gao, K., et al. Chem. Mater. 2018, 30, 5429. (c) Li, S.; Ye, L.; Zhao, W., et al. J. Am. Chem. Soc. 2018, 140, 7159. (d)
Yuan,J.; Zhang, Y.; Zhou, L., et al.Joule 2019, 3, 1140. (e) Cui, Y.; Yao, H.; Zhang, J., et al. Nat. Commun. 2019, 10, 2515.

(4) (a) Huang, W.; Cheng, P.; Yang, Y. M.; Li, G.; Yang, Y. Adv. Mater. 2018, 30, 1705706. (b) Li, H.; Lu, K.; Wei, Z. Adv. Energy Mater. 2017, 7, 1602540. (c) Baran, D.; Ashraf, R. S.; Hanifi, D. A., et al. Nat. Mater. 2017, 16, 363. (d) Lu, L. Y.; Kelly, M. A.; You, W.; Yu, L. Nat. Photonics 2015, 9, 491. (e) Liu, X.; Yan, Y.; Yao, Y.; Liang, Z. Adv. Funct. Mater. 2018, 28, 1802004. (f) An, Q.; Zhang, F.; Zhang, J.; Tang, W.; Deng, Z.; Hu, B. Energy Environ. Sci. 2016, 9, 281.

(5) (a) Zhang, M.; Gao, W.; Zhang, F., et al. Energy Environ. Sci. 2018, 11, 841. (b) Nian, L.; Gao, K.; Jiang, Y., et al. Adv. Mater. 2017, 29, 1700616. (c) Gasparini, N.; Jiao, X.; Heumueller, T., et al. Nat. Energy 2016, 1, 16118.

(6) (a) Zhang, T.; Zhao, X.; Yang, D.; Tian, Y.; Yang, X. Adv. Energy Mater. 2018, 8, 1701691. (b) Fan, B.; Zhong, W.; Jiang, X-F., et al. Adv. Energy Mater. 2017, 7, 1602127. (c) Chen, Y.; Qin, Y.; Wu, Y., et al. Adv. Energy Mater. 2017, 7, 1700328. (d) Lu, H.; Zhang, J.; Chen, J., et al. Adv. Mater. 2016, 28, 9559. (e) Chen, Y.; Ye, P.; Zhu, Z., et al. Adv. Mater. 2017, 29, 1603154. (f) Zhu, Y.; Gadisa, A.; Peng, Z., et al. Adv. Energy Mater. 2019, 9, 1900376. (g) Hadmojo, W. T.; Wibowo, F. TA.; Lee, W., et al. Adv. Funct. Mater. 2019, 29, 1808731.

(7) (a) Ma, X.; Mi, Y.; Zhang, F., et al. Adv. Energy Mater. 2018, 8, 1702854. (b) Wang, C.; Xu, X.; Zhang, W., et al. Nano Energy 2017, 37, 24. (c) Zhang, J.; Liu, W.; Chen, S.; Xu, S.; Yang, C.; Zhu, X. J. Mater. Chem. A Mater. Energy Sustain. 2018, 6, 22519. (d) Hu, H.; Ye, L.; Ghasemi, M., et al. Adv. Mater. 2019, 31, 1808279. (e) Li, Z.; Xu, X.; Zhang, W., et al. Energy Environ. Sci. 2017, 10 , 2212. (f) Yao, H.; Cui, Y.; Yu, R.; Gao, B.; Zhang, H.; Hou, J. Angew. Chem. Int. Ed. 2017, 56, 3045. (g) Fan, B.; Zhu, P.; Xin, J., et al. Adv. Energy. Mater. 2018, 8, 1703085. (h) Nian, L.; Kan, Y.; Wang, H., et al. Energy Environ. Sci. 2018, 11, 3392.

(8) (a) Ma, X.; Gao, W.; Yu, J., et al. Energy Environ. Sci. 2018, 11 , 2134. (b) Kan, B.; Yi, Y-Q-Q.; Wan, X., et al. Adv. Energy Mater. 2018, 8, 1800424. (c) Jiang, W.; Yu, R.; Liu, Z., et al. Adv. Mater. 2018, 30, 1703005. (d) Yu, R.; Zhang, S.; Yao, H., et al. Adv. Mater. 2017, 29, 1700437. (e) Cheng, P.; Zhang, M.; Lau, T. K., et al. Adv. Mater. 2017, 29, 1605216. (f) Liu, T.; Guo, Y.; Yi, Y., et al. Adv. Mater. 2016, 28, 10008. (g) Liu, T.; Luo, Z.; Chen, Y., et al. Energy Environ. Sci.. Doi: 10.1039/C9EE01030K. (h) Lv, R.; Chen, D.; Liao, X.; Chen, L.; Chen, Y. Adv. Funct. Mater. 2019, 29, 1805872. (i) Jiang, H.; Li, X.; Wang, J., et al. Adv. Funct. Mater.. Doi: 10.1002/ adfm.201903596. (j) Zhang, M.; Xiao, Z.; Gao, W., et al. Adv. Energy Mater. 2018, 8, 1801968. (k) Naveed, H. B.; Ma, W. Joule 2018, 2, 621. (l) An, Q.; Zhang, F.; Gao, W., et al. Nano Energy 2018, 45, 177.

(9) Zhao, W.; Li, S.; Zhang, S.; Liu, X.; Hou, J. Adv. Mater. 2017, 29, 1604059.

(10) Gao, H-H.; Sun, Y.; Wan, X., et al. Adv. Sci. 2018, 5, 1800307.

(11) Xie, Y.; Yang, F.; Li, Y., et al. Adv. Mater. 2018, 30, 1803045.

(12) Xu, S.; Zhou, Z.; Liu, W., et al. Adv. Mater. 2017, 29, 1704510.

(13) Liu, W.; Zhang, J.; Zhou, Z., et al. Adv. Mater. 2018, 30, 1800403.

(14) Zhou, Z.; Xu, S.; Song, J., et al. Nat. Energy 2018, 3, 952. 